\title{
JUSTO SIERRA EN LA MIRA DE VICENTE RIVA PALACIO *
}

Clementina Díaz y de Ovando

La República. Periódico político y literario, dirigido por el novelista Pedro Castera, empezó a publicar a partir del 3 de enero de 1882 y, durante los meses de febrero a marzo, una serie de artículos con el título de Geros en torno a diferentes escritores mexicanos, asi como varias tradiciones en verso de algunas calles de la ciudad de México, firmadas con el seudónimo de "Cero".

Después de muchas especulaciones sobre quién sería "Cero" se supo que era nada menos que el general Vicente Riva Palacio, historiador, novelista, cuentista, periodista combativo y satírico, político, diplomático y una de las personalidades más atractivas e importantes en la cultura mexicana del siglo xix.

En los primeros artículos, "Cero" fue preparando el terreno para que los lectores de La República se interesaran en las semblanzas de los escritores de los que se ocuparía y a los que con singular gxacia y desenfado pincharía con su "alfiler de oro".

Estas extraordinarias semblanzas que La República insertó en sus páginas, junto a otras que el articulista escribió después como las de Juan de Dios Arias, Peón Contreras, José María Roa Bárcena y Alfredo Bablot, fueron reunidas en el volumen Los ceros. Galería de Contemporáneos. Por Cero. El libro salió de las prensas de uno de los grandes editores de la época, Francisco Díaz de León, e ilustrado con espléndidos retratos litográficos ejecutados por el gran artista Santiago Hernández.

El primer retrato literario que escribe "Cero" es el del viernes 6 de enero y está dedicado a Justo Sierra. Los artículos de los días 4 y 5 le han servido a Riva Palacio para llevar adelante su propósito y discutir la figura del positivista Sierra y contestar al mismo tiempo los sarcas. mos que este joven escritor le lanzó el día 5 de diciembre de 1881 en la Cámara de Diputados, sesión en la que se pusieron en el tapete las dos posiciones ideológicas en lucha esoś afíos: la metafisica y el positivismo.

* En este año de 1982 se cumple un siglo de la publicación del libro Los ceros. Galeria de Contemporáneos. Por Cero. Valga este modesto recordatorio de obra tan trascendente para la cultura mexicana. 
"Cero" puso en la semblanza de Sierra un poco más de su desenfadada ironía y retozos acostumbrados, y esto ha sido motivo de que se juzgue a Riva Palacio como un malqueriente y un envidioso de Sierra.

El crítico José Luis Martínez al opinar sobre Los ceros dice: "Sólo en algún caso, como en la estampa de Justo Sierra parece que una secreta envidia enturbia sus líneas." 1

¿Por qué había de tenerle Riva Palacio envidia a Sierra? Sierra era a la sazón un joven de treinta y cuatro años, talentoso periodista polémico, director de La Libertad, "diario liberal conservador", desde donde Sierra -asegura su biógrafo Agustín Yáñez- daría las normas para un programa nacional de gobierno. Sorprendente poeta, novelista, dramaturgo, orador, historiador, profesor de la Escuela Nacional Preparatoria, diputado al Congreso de la Unión; todo eso era Sierra. Pero a sus cincuenta años Riva Palacio era "una gloria nacional", defensor de la patria con la espada y con la pluma en los días aciagos de la Intervención Francesa; poeta, historiador, novelista famosísimo y muy leído, facetas que el mismo Sierra había pulido catorce años atrás en sus "Conversaciones del domingo". (El Monitor Republicano, 12 de abril de 1868.)

Nada os diré del carácter ni del corazón de Vicente Riva Palacio; la República entera sabe en esto a qué atenerse, y la historia recoge ya datos para formar con ellos una brillante página. Como literato, es notable y delicioso intérprete de las brisas y de los vaivenes del mar y de la siesta, cosas todas gratas a nuestro corazón, como el recuerdo de la tierra natal. ¿Y como pintor de costumbres? Riva Palacio posee bellísimos romances de costumbres, en que se adunan la armonía, la fluidez admirable del verso, y un estudio que inmediatamente se conoce profundo y lleno de veracidad. ¿Y como novelista? Detengámonos; la preciosa novela que nos está leyendo en las veladas, y que el público conocerá bien pronto, nos dará al formar el objeto de un estudio que publicaremos aquí la ocasión de conocex bajo este punto de vista las cualidades del autor ...2

1 La expresión nacional, México, Imprenta Universitaria, 1955, p. 202 ,

2 Sierra alude a la novela Calvario y Tabor (1869), algunos de cuyos capítulos Riva Palacio leyó en una de las veladas literarias de principios de 1868 " $L a$ Orquesta, el 21 de marzo de 1868, se refería al exito que la lectura de Calvario y Tabor había alcanzado en esas veladas literarias.

Cuantos tuvieron el placer de escuchar aquella lectuxa han quedado guatamente sorprendidos ante la novedad, sentimiento e interés de que está llena la obra. 
Y en cuanto a la vida pública, Riva Palacio, fueta de no haber logrado la meta a la que aspira todo buen mexicano cuando entra a la política: la presidencia de la República, lo habia sido todo, general, diputado, gobernador, consejero, ministro de la Suprema Corte de Justicia, ministro de Fomento, y solamente la intriga y el miedo a su talento lo habían desplazado del palenque político, como aseguraba $L a$ Patria en su "Postumógrafo" el día $1^{\circ}$ de noviembre de 1878.

La nación reconocida al que fue Ministro de Fomento Gral. Vi. cente Riva Palacio.

Tuvo mil envidiosos: el talento / siempre seguido de la envidia va; después de ser Ministro de fomento / sembró de gratitud un sentimien. to en los pueblos, que nunca morirá.

Riva Palacio no tenía por qué envidiar el que Sierra fuera el más celebrado poeta en esos momentos, ni tampoco el talento de Sierra, ni su ascensión política. La cumbre que Sierra escalaría más tarde como "Maestro" y como una de las figuras más eminentes en nuestra historia cultural, no era posible que Riva Palacio la entreviera ese año de $\mathbf{1 8 8 2 .}$ Y cuando Sierra la alcanza, Riva Palacio ya no la ve, ha muerto antes. Tampoco atestigua el triunfo del positivismo y sus consecuencias como programa político. No mira el desencanto de Sierra por la escuela positiva, ni oye a Sierra cantar la palinodia ante el asombro de los pre. paratorianos, reunidos en el Generalito, un día de julio de 1908, según recuerda Francisco Monterde, entonces alumno del primer año de preparatoria.

Sierra, dúctil como el oro, muy al final de su vida se aparta del positivismo y se torna al idealismo. Justo Sierra, dice uno de los miem bros del Ateneo de la Juventud, Antonio Caso, "llevaba a sus discípulos del escepticismo de la ciencia positiva al terreno de lo que es la cultura. Sus bienes y valores; sus vicisitudes, sus triunfos y sus héroes". Por su parte, Alfonso Reyes, otro ateneísta, agradece a Justo Sierra el

Evidentemente es una producción notable, la primera en su género de las que ha visto la luz pública.

Histórica y de costumbres, esa novela encierra hechos y descripciones que sólo pudo hacer quien, como su autor, ha visitado los lugares en que pasan los sucesos que relata.

Los amigos de Vicente Riva Palacio se han acercado suplicándole que la publique.

Nosotros secundamos igual excitativa pues con esa obra adquirirá nuestra li. teratura una joya de gran valia. 
que haya hecho "sospechar a su generación que había sido educada en una impostura".

Pero esta nueva actitud filosofica de Sierra, comentada y alabada por los ateneístas, quedaba muy lejos del año de 1882, año en que Sierra exa conocido como un apasionado positivista.

Si se examinan los antecedentes de la pintura que de Sierra hizo Riva Palacio en Los ceros, puede verse que no hay escondida ni torturante envidia, y que todo se reduce a una buena pelea de carácter ideológico que, como se sabe, son siempre más enconadas, pues ninguno de los gladiadores desea ser el perdidoso, el necio, y las más veces, esos altercados ideológicos separan para siempre "

La historia de la semblanza de Sierra, en la que para darle gustoso sabor, Riva Palacio le puso su cascarita de naranja agria, encuentra su causa -a mi entender, repito- en dos discusiones cuyo fondo eran las creencias filosóficas de los contendientes: la escuela metafísica y el positivismo.

La Repriblica, en esos años 1881-1882, se hallaba en pugna sin tregua ni perdón con La Libertad. Riva Palacio, siguiendo sus propias convicciones krausistas toma el partido del periódico en que colaboraba, y qué mejor oportunidad para hacer zumba del positivismo que el boceto de uno de sus principales adalides, ya que como tal era considerado Sierra.

El doctor Manuel Flores en "Apuntes biográficos del doctor Gabino Barreda", publicados en La Libertad el 15 de marzo de 1881, sostenía: "Hoy es bien sabido que el Lic. Sietra, director de La Libertad es uno de los positivistas más ardientes."

Además de la porfía entre La Libertad y La República, Justo Sierra y Riva Palacio tenían la suya personal, la que tabía surgido en la Cámara de Diputados el mes de diciembre de 1881, a propósito de la discusión sobre la expropiación como causa de utilidad pública.

El 2 de diciembre de 1881, Riva Palacio (Diario de los Debates) en el uso de la palabra "contestó los argumentos de C. Enríquez y además recurrió a varias citas históricas para demostrar el acierto de la comisión al consultar el artículo $3^{\circ}$ que se estaba discutiendo".

Riva Palacio, para defender sus puntos de vista, hizo la historia del derecho de la propiedad, trajo a colación a los brahamanes, y pasando por los hebreos, los griegos, los romanos llegó al derecho germánico, sin descuidar en su alegato el derecho divino. Como buen idealista y 
romántico no le importó que sus citas se apegaran estrictamente a la verdad y a la imparcialidad históricas, en esto seguía la afirmación de Krause,

la historia que se redujera a describir con mayor o menor imparcialidad el mero suceso histórico revelaría una noción torcida de su misión, porque lo particular lo positivo histórico, es inteligible sólo como una manifestación limitada y parcial de la esencia divina. ${ }^{3}$

En la sesión del 5 de diciembre, se lee en El Diario de los Debates: "El C. Sierra habló en contra del dictamen y rectificó varias inexactitudes en que incurrió el señor Riva Palacio al citar hechos históricos en una de las sesiones anteriores."

Ese día 5 de diciembre, Sierra, bajo la égida del positivismo, que "intentó recuperar al hombre concreto del idealismo y del romanticismo, dejándolo en pura racionalidad", y con los recursos de esta escuela: el dato histórico y la imparcialidad, corrige una a una las inexactitudes históricas en que incurrió Riva Palacio, y demuestra a éste que su historia no es científica y que el rigor histórico se había diluido en la brillantez de la forma. Y con toda claridad, sin lugar a dudas, Sierra fija su posición: entre la escuela metafísica y la escuela positivista no hay entendimiento posible.

Y sin embargo, señor, es precisamente en esta cuestión, es precisamente en esto que yo llamaría la génesis del derecho de propiedad, en donde empiezan nuestras disidencias que se van ahondando cada vez más, hasta llegar a una cuestión práctica en que hoy, entre los que pertenecen como yo, en clases de humildes adictos a la escuela histórica, y los que pertenecen a la escuela metafísica hay un abismo infranqueable.

A Sierra siguió en el uso de la palabra el diputado Diego Baz, y al impugnar el discurso de Sierra hizo notar la rivalidad entre Riva Palacio y Sierra.

No es mi propósito seguir al Sr. Sierra en el campo histórico, porque su peroración en cuanto a tal materia se refiere ha tenido digámoslo así, el carácter de un torneo de erudición sostenido contra el Sr. Riva Palacio.

3 Juan Morillas, El krausismo español, México, Fondo de Cultura Económica, 1956, p. 40. 
Esta discusión en la Cámara fue la gota que, por ambas partes, derramó el vaso. $Y$ las dos maneras de concebir la tarea histórica: la idealista y la positiva separaron, en esta ocasión, a los que antaño com. partieron la alegria de una verdadera amistad intelectual.

Después de la rotunda declaración de Sierra, de ese rompimiento tan definitivo, el Cero de Sierra se presenta diáfano en sus motivaciones: es la contestación de un jacarandoso metafísico a un positivista demasiado ferviente. Sin embargo, cl "alfiler de oro" de Riva Palacio apenas rasga la persona de Sierra; levanta un poco la piel en la parte endeble de su obra literaria, el teatro y la novela; retrocede admirado ante su poesía y, eso sí, cala en su actitud filosófica.

Con el truco que Riva Palacio ha venido utilizando: el de ser un provinciano deslumbrado por las personalidades literarias de la capital, se apercibe a la contienda.

"Cero" dice que allá en su pueblo deseaba conocer más que a ningún otro de los conspicuos literatos de la capital a Justo Sierra, de quien supo por el periódico El Renacimiento (1869) que hasta su rincón llegaba, para solaz suyo y del cura harto "tolerante". Unos cuantos piquetitos a Sierra aquí y allá para abrir boca, y "Cero" prosigue sus impresiones.

Por fin, "Cero" es presentado a Justo Sierra, pero joh desencantol, el sentimental, el soñador poeta de "Playeras" leía en esos momentos una entrega de la recién aparecida revista del doctor Parra: El Posi. tivismo; del primer número daba noticia La Patria ese día 6 de enero de 1882: "EL positivismo. Ha circulado la primera entrega de esta publicación."

De paso "Cero" critica el formato de la revista, el grabado que re. presenta a Sócrates, y da la opinión que de este filósofo tiene Comte. Todo parece a "Cero" una incongruencia. Sin decir el nombre ras" guña levemente al periódico La Libertad, y también a sus redactores, en especial a Francisco Bulnes, al que tampoco nombra. Para su identificación da como señas su inteligencia, su seudónimo Junius y el periódico en que colaboró: El Domingo. Conforme a sus planes, "Cero" describe físicamente al poeta yucateco Justo Sierra, marcado ya por los años, por el dolor y por el positivismo: "nieve por dentro y por fuera", pues esta filosofía ha ahogado el maravilloso sentimiento brotado del corazón que Sierra revelara en sus primeras composiciones "Playeras", 


\section{"El canto de las hadas", "Nocturno", "Miriam", su drama "Piedad"," y sus novelas El ángel del porvenir y Confesiones de una pianista.5}

4 De este drama Piedad escrito por Sierra en sus mocedades, Enrique Olavarría y Ferrari en su Reseña histórica del teatro en México, dice que se representó el 17 de marzo de 1870 en el Teatro Nacional, con gran éxito a beneficio de la viuda e hijos del actor Merced Morales.

Todas las localidades se vieron ocupadas por lo muy escogido de la sociedad mexicana, a la cual el actor español Eduardo González ofreció el estreno del drama nuevo y original de Justo Sierra, intitulado Piedad, cuya acción comienza en México $\mathrm{y}$, sin interrumpir la unidad del tiempo, se desenlaza rápidamente en Tacubaya. La obra no exenta de defectos, pero sembrada de bellezas de primer orden, gustó mucho y fue muy aplaudida, especialmente en su segundo acto, que es magnífico, y por lo fuerte y terrible de las situaciones casi toca en lo trágico. México, Biblioteca Porrúa, 1961, p. 808.

5 Las confesiones de un pianista, citadas aquí por Riva Palacio, se publicaron en El Domingo (tomos in y iv, 1871). Con motivo de la pugna entre Sierra y los redactores de La República en 1882 -pugna que se prolongó durante muchos meses- éstos aprovecharon la oportunidad de seguir molestando a Sierra y de paso a Francisco Sosa, autor de la leyenda Magdalena, también publicada en el tomo I del Domingo (1871), cuyo tema era el muy romántico de los amores de conveniencia y los matrimonios ventajosos.

El 5 de mayo de 1882 La República intencionadamente publicó estos párrafos:

A La República - Personas de buen gusto en materia de letras nos suplican que preguntemos a nuestro apreciable colega $L a$ República si se está haciendo un sobretiro de los folletines de Justo Sierra, intitulado Confesiones de un pianista. Al obsequiar con placer la súplica que se nos ha hecho aprovechamos la oportunidad para felicitar a nuestro colega por esa feliz idea que tuvo de reimprimir esa obra publicada por primera vez en El Domingo.

Las anteriores líneas pertenecen a El Nacional. La República se felicita de que personas de buen gusto en materia de letras, deseen se haga un sobretiro de la lindísima novela de Justo Sierra, y agradeciendo las galantes frases que el colega nos dedica, le manifestamos que ya se procede a hacer el sobretiro para obsequiar sus deseos y con franqueza vacilábamos a que dar preferencia en la publicación, si a Las confesiones de un pianista o a la preciosa novela del Sr. Sosa titulada Magdalena.

El Nacional (periódico dominical) de 7 de mayo de 1882, pescó la burla y contestó ese día a La Repríblica. Francisco Sosa encargó a la redacción del Nacional hiciera las aclaraciones necesarias, y de paso dio un zaspón a Pedro Castera, director de La República.

La leyenda intitulada Magdalena fue escrita sin pretensión alguna no llevó prólogo ajeno, ni apéndice de cartas de amigos, ni se puso a la venta. El autor de aquel ensayo es el primero en reconocer los innumerables defectos que encierra; todavia más tuvo el buen juicio de conocer que no poseía dotes de novelista, y ha largos años que no escribe, ni aún siquiera lee, obras de ese género. Demás, está pues, la burla embozada de La República, burla en que no quisiéramos ver envuelto al Sr. Sierra. El autor de Magdalena tendría orgullo, si to fuera de las 
Composiciones con las que aquel inspirado colegial admiró a los concurrentes de las veladas literarias en casa de Altamirano, Riva Palacio y Martínez de la Torre. ¡Cuán lejos -añora con tristeza "Cero"- quedan ya esos años!

Después de esta reflexión en la semblanza de Sierra que apareció en el libro Los ceros, Riva Palacio añadió un cuento que no figura en la primera versión, la que publicó el 6 de enero La República.

Riva Palacio fue siempre fue muy dado a intercalar cuentos en sus artículos; en las "Oberturas toda Orquesta" que escribió para $\mathrm{La} O \mathrm{Or}$ questa (1870), hay unos cuentecillos que tienen toda la oportunidad, la gracia, la sutileza y la picardía del pueblo mexicano.

Vuelto a las andadas, le endilga a Sierra un mexicano cuento de pericos, cuya moraleja es exhibir el error de Sierra, quien siendo ante todas cosas un poeta, anda "metido en camisa de once varas" alardeando de filósofo positivista, y hablando de Comte y demás corifeos.

A seguidas del cuento, cita bellamente la lucha entre Ormuz y Arimán, y la compara a la batalla espiritual que libra Sierra entre su vocación de poeta y esa su extraña manía positivista.

Y abandonando el juego y el cuento, "Cero" con la mayor seriedad pasa a la crítica de la poesía de Sierra. Ante esta poesía auténtica confiesa su admiración y elogios. Sale a la defensa de las metáforas, de las imágenes audaces y desconcertantes de Sierra, incomprendidas por muchos y señaladas por otros como defectos. Para "Cero" son todo lo contrario: manifiestan la inteligencia de Sierra, lo "aventajado de su talla" y su desdén por lo raquítico. Ya el periódico Mefistófeles, el 3 de noviembre de 1877 , se burlaba de las metáforas de Sierra que debían servirle para inmortalizar su vanidad.

Confesiones de un pianista, porque comprende bien que entre el Sr. Sierra y él hay la misma distancia que entre Jorge lssacs y el $\mathrm{Sr}_{\text {. Castera. }}$

Una prucba inrefutable de lo dicho, es que contando como cuenta el Sr. Sosa con el folletín del Nacional, no ha pensado ni por un momento en fastidiar a los lectores de este periódico insertando en él la leyenda de que habla la República..

Por encargo de nuestro compañero de redacción hacemos estas explicaciones: El día 8 de mayo La República se lanzó contra El Nacional y salió por los fueros de Pedro Castera y de su novela Carmen, ya que todas las aclaraciones de El Nacio. nal, exan pullas enderezadas contra Pedro Castera. El 9 de mayo La República decia:

A La Libertad. Pedro Castera repite al apreciable y grandísimo colega las más expresivas gracias por el ofrecimiento que hace de seguir ocupándose de su hu. milde producción. 
- Mira Mefístofeles, mira, aquí está el sepulcro de un gran poeta que no confió a sus amigos el cuidado de inmortalizar su nombre. -¿QQuién es?

-Escucha.

-Ciclopes de la luz besad la tierra donde yazgo triunfante!

Justo Sierra.

Para dar mayor énfasis a sus argumentos, "Cero" transcribe un párafo de Brieva y Salvatierra sobre Esquilo, "el poeta de la energía y la fuerza", que aplica a Justo Sierra, "escrito -dice- por mano diestra aclara la idea expresada mejor que cuanto comentario pudiera yo hacer".

Después de ensayar en la poesía de Sierra la imparcialidad -no ha mezclado al comentarla sus divergencias- de hacer gala de crítico entendido y justiciero, "Cero", dado su natural zumbón y combativo, hace referencia a algunas opiniones de Sierra que figuran en su Compendio de historia de la antigüedad. Para llegar al comentario de estas opiniones, Riva Palacio se detiene y explica el porqué Sierra gusta en sus versos de lo descomunal, de lo titánico,

no parece sino que se nutrió, en sus primeros años de educación, con las tradiciones chaldeobabilónicas de Beroso, con los relatos del Génesis, con los comentarios del padre Calmet, con la Gigantomaquia y la Titanomaquia helénicas, con la guerra de los Aloades contra los dioses, o cuando menos con la historia de los "Doce pares de Francia", por el arzobispo Turpin, en donde andan a las vueltas Fierabrás y Floripes. ${ }^{6}$

Es decir, el ahora positivista Sierra, supo y sufrió la influencia de las tradiciones y leyendas, tan aborrecidas por la historia cientifica, tradiciones y mitos que dan a su poesía novedad y originalidad.

"Cero" ha llegado al punto que le interesa glosar, al sostenido por Sierra en su Compendio de historia de la antigüedad, con respecto a Louis Jacoillot, a quien llamaba "mentiroso y charlatán". Sierra estaba en lo cierto, la crítica de hoy día corrobora su dicho y aun va más allá, ya que considera a Jacoillot como un impostor y a sus libros sobre temas hindúes verdaderas patrañas. Al referirse Riva Palacio a la tesis que sostenía la prioridad cronológica de la India sobre Egipto, Sierra había escrito en su Compendio,

6 Los ceros, p. 51 
sabios de primer orden como Heeren, Creuzer y W. Jones y organizadores de datos históricos de mediana inteligencia, pero de voluminosa erudición, como César Cantú, sostuvieron la tesis de la prioridad cronológica de la India sobre Egipto: esta tesis abandonada ya por todos los indianistas serios, apenas cuenta entre sus defensores a uno que otro cuentista de la categoría de $M_{\text {. Jacoillot. }}{ }^{7}$

Al referirse Sierra al mito de Krishna adicionado después de la introdución del cristianismo a la India, Sierra vuelve a mentar con igual desdén a Jacoillot, pues este mito, "ha motivado la redacción de un libro lleno de fantaseos y errores de tono declamatorio".

Estas afirmaciones de Sierra no podía dejarlas pasar inadvertidas en su Cero Riva Palacio. No se necesita mucha perspicacia para dar con el busilis de la cuestión, y ver que las relacionó con el discurso que Sierra pronunció en la Cámara de Diputados el $\mathbf{5}$ de diciembre de 1881, discurso en el que Sierra le había negado validez a sus citas históricas. En esa impugnación, Sierra, aunque sin decirlo abiertamente, sin nombrar a Jacoillot, pero con bastante claridad para que lo entendiera Riva Palacio, deja traslucir que toda la información del general sobre la India y los brahamanes, provenía no de documentos históricos, sino del venero de un redactor de obras no científicas, bien inclinado a lo novelesco, a la narración de aventuras, como era Louis Jacoillot, ya que pese a haber residido mucho tiempo en. la India, mezclaba la historia con las leyendas y las fantasías.

Por aquellos años Jacoillot gozaba de gran popularidad én México; los periódicos anunciaban sus obras, y la biblioteca de la Escuela Nacional Preparatoria de esa época adquirió todas sus obras. Todavía pueden consultarse en la biblioteca de la Preparatoria los libros de Jacoillot en la edición francesa; en cambio, no hay un sólo ejemplar de aquella Historia de la antigüedad que Sierra escribió para sus alumnos del año de 1878, en que fue nombrado profesor de historia general en la Escuela Nacional Preparatoria. ${ }^{9}$

7 Obras completas del maestro Justo Sierra, t. $\mathrm{x}, \mathrm{p} .32$

8 Op. cit., p. 304. Sierra se refiere al Iibro de jacoillot, Cristna et le Crist, Paris, 1874.

${ }^{9}$ El Compendio de historia de la antigüedad que Sierra escribió para sus alumnos de la Escuela Nacional Preparatoria en 1878, en que fue nombrado profesor de esta Escuela, se publicó primeramente por entregas, con el título de Compendio de Historia General. La Patria (3 de enero de 1878) en su sección "Sucesos del día" acusaba recibo de la primera entrega. 
Regresando a Los ceros, Riva Palacio, bajo la apariencia de eruditas reflexiones históricas, responde socarronamente a Sierra, poniéndolo en parangón por sus conocimientos sobre el Oriente con el célebre orientalista y arqueólogo francés Charles Lenormant, y aclarando que Sierra no soporta a Jacoillot

no tanto por los prodigios que atribuye a la fuerza magnético-animal, como porque sostiene que los Vedas son la fuente de todos los libros sagrados, persas, egipcios, búdicos y judíos, y porque cree que el Pentateuco fue escrito después de la cautividad de los israelitas, cuando Justo lo admite contemporáneo de los libros chaldeo-egip$\operatorname{cios}^{10}$

O lo que es lo mismo, a Sierra le carga Jacoillot no por sus fantasías, sino por sostener otra tesis contraria a la del orientalista Justo Sierra.

En favor de "Cero" puede decirse que la historia de nuestros días no desdeña las leyendas ni los mitos, sino los considera parte de nuestro propio ser.

Una vez que "Cero" se ha sacado la espina que desde hacía un mes tenía atragantada, vuelve a comentar la obra literaria de Justo Sierra: la novela y el teatro.

Cita la novela juvenil de Sierra El ángel del porvenir, publicada en El Renacimiento el año de 1869 , y de este modo da un rápido pinchazo a Sierra. En El ángel del porvenir, Sierra, al decir de Riva Palacio, se perdió buscando el ángel y atisbando el porvenir, y "aún hoy mismo -comenta "Cero"- no se puede afirmar que Sierra sepa quién iba a ser el 'ángel', quizá el editor".

Hemos recibido la primera entrega de una notable publicación que ha comenzado a ver la luz, con el título de Compendio de Historia General. El cono. cido escritor Justo Sierra, es el autor de esta obra, y se propone queden allá registrados los hechos principales desde los orígenes del hombre, hasta nuestros días; de manera que se note que forma un todo regido por leyes generales, con la aproximación que el estado de la ciencia permite.

Con el título de Compendio de historia de la antigüedad, Sierra publicó su texto el año de 1880, con pie de imprenta de La Libertad. El 19 de enero de 1881, La República en su gacetilla, daba las gracias por el envío del libro.

COMPENDIO DE HISTORIA. - Hemos recibido un tomo del Compendio de

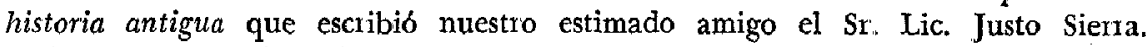
Dicha obra está adoptada justamente, como texto en la Escuela Nacional Preparatoria. Al dar las gracias a su autor, le felicitamos cordialmente, por el servicio que ha prestado a las letras.

10 Los ceros, p. 52. 
Todavía en 1874 en El Ahuizote (20 de marzo) bromeaba sobre esta novela en una caricatura de "Galería de Contemporáneos", en donde Sierra aparece con sus alas de ángel y con esta leyenda: El Angel del Porvenir. Y con una cita de los versos de Sierra: "Ámbar que duerme en nítidos olanes."

Sierra era muy consciente de las fallas de esta novela; él mismo se definió así: "el novelista que no escribió su novela".

Años después de haberse publicado Los ceros, Sierra, en 1901, parece recoger la alusión de Riva Palacio y en "Una tumba, Cartas a Urbina", dijo por qué había escrito esta novela.

El Renacimiento, ayuno de suscripciones aunque no de alabanzas, tenía necesidad de "inflar la suscripción" por medio de una novela sensacional. Sierra, en cónclave de amigos, fue señalado para esta tarea. Urgido por el compromiso moral contraído con El Renacimiento puso manos a la obra; escribió un prólogo que le permitió ganar quince días, prólogo que fue ampliamente explicado y elogiado por José Rafael de Castro. ${ }^{11}$

$Y$ en la búsqueda del argumento, Sierra confiesa que echó mano del acontecer cotidiano que le proporcionó el material para "ensartar capítulos de puerilidades y tonterías empapadas en un donjuanismo satánico e infantil".

La novela, compuesta de episodios, carecía de argumento; el tema a desarrollar -dice Sierra- era éste:

la mujer mexicana será el ángel del porvenir, ella nos salvará socialmente, pero se regenerará por el sentimiento religioso, substituyente de la devoción y la superstición; el amor de la patria será parte integrante de esta religión como en los Estados Unnidos. Tal era ei tema; quizá si hubiese durado algo más El Renacimiento, habría dado con el argumento, ¿quién sabe?

Pero si bien Sierra no dio con el argumento de esta novela, al columbrar el porvenir, al hacer entrar a su novela a Gambetta, adivinó - dice lleno de alborozo- la ruina del imperio napoleónico y la "aurora de la Tercera República". ${ }^{12}$

En este don adivinatorio de Sierra, hace hincapié el crítico Francisco González Guerrero. Cuando aún no se publicaba El ángel del porve-

11 El Renacimiento, México, 1869, I, pp. 133-136.

12 Obras completas del Maestro Justo Sierra, "Viajes", pp 202-203. 
nir en las Obras completas del maestro Justo Sierra, González Guerrero escribió tres artículos sobre esta novela en el periódico El Universal, los días 27 de diciembre de 1947 y 3 y 10 de enero de 1948 .

En el primero, 27 de diciembre de 1947, titulado "Una obra rara de Justo Sierra. El ángel del porvenir. Palabras proféticas", 13 afirma

todo el plan de la obra está ya en germen en el primer párrafo del prólogo y ya en fruto en la última línea que sirve de epígrafe al libro. In servitute dolor, in libertate labor. Es muy interesante su sentido profético y, literariamente es lo más valioso de la obra.

En el artículo del 3 de enero de 1948, González Guerrero dice que El ángel del porvenir

es una obra, entre las de Justo Sierra, de calidad inferior ... teniendo en cuenta las circunstancias en que fue escrita, es un documento revelador de sus facultades literarias malgastadas por el apremio de la improvisación.

El artículo de González Guerrero termina citando el juicio que Riva Palacio escribió en Los ceros sobre El ángel del porvenir, con el que está enteramente de acuerdo.

13 El Siglo xix de 9 de agosto de 1843 anunciaba que la obra de Bretón de los Herreros, Don Fernando el emplazado, se vendía en la librería de la calle de la Joya número 5. Justo Sierra, seguramente inspirado en esa comedia, escribió teniendo como colaborador a Enrique Olavarría Ferrari, su versión sobre este tema y con el mismo título Don Fermando el emplazado. La obra fue escrita con el noble fin de allegarse fondos que se destinatian a levantar una estatua de Joaquín Fernández de Lizardi. En El Renacimiento, Manuel Peredo el 12 de marzo de 1869 , hacía un llamado al público para que acudiese a la representación de la obra el lunes 15 de maxzo. Peredo advertía que

no hay que pedir al drama, mérito literario en razón de haber sido hecho sólo como un pretexto para presentar aquel juguete de óptica.

Desde el mes de enero se anunciaba en los periódicos como una novedad teatral el espectáculo "espectros luminosos", que tanto éxito había alcanzado en Paris y Nueva York y que se presentaría en el Teatro Iturbide. La noche del 15 de marzo en que Sierra y Olavarría ofrecieron al público mexicano su obra Don Fernando el emplazado, los espectros luminosos una de ias atracciones de la representación esíu. vieron a cargo del barón Gustavo Gostkowski. A pesar del llamado al público del Dr. Peredo, éste no acudió y la representación fue un fracaso teatral y pecunario.

Con anterioridad a la puesta en escena de Don Fernando el Emplazado, periodico como El Constitucional ironizaba a Sierra y a Olivarría; La Tarántula el 4 de marzo de 1869 daba sus tirones de orejas al "Dr. Hermógenes" seudónimo de Jesús Garcia Gutiérrez por atacar sin fundamento a Don Fernando el emplazado.

Sietra y Olivarría nunca permitieron la impresión de Don Fernando el emplazado, con esta negativa jugó Riva Palacio en el Cero de Sierra 
De ese mismo año 1869 en que apareció El ángel del porvenir, Riva Palacio comenta la obra teatral de Sierra, escrita en colaboración con Enrique Olavarría y Ferrari, Don Fernando el emplazado, representada el 15 de marzo de 1869 en el teatro Iturbide, con el propósito de obtener fondos para levantar una estatua al "Pensador Mexicano". La obra resultó un fracaso, pues fallaron los trucos luminosos. Acaso los espectros por haber renegado de ellos Joaquín Fernández de Lizardi, hijo de la Ilustración y enemigo, por lo mismo, de las supersticiones, se negaron a salir a escena y la función fue un fiasco. ${ }^{14}$

Riva Palacio dice que en la obra de Sierra, don Fernando y los Carvajales hablaban en Víctor Hugo, hoy, bajo la influencia de la escuela positiva, afirma, hablarían en Spencer y serían para mayor desdicha de los Carvajales, positivistas.

"Cero" en esta semblanza ha repasado varios aspectos de la perso" nalidad y obra de Sierra: como historiador, filósofo, poeta, novelista y dramaturgo. No obstante el tono humorístico con que está escrito, Riva Palacio ha reconocido la inteligencia privilegiada, la inspiración, la rica y varia erudición de Justo Sierra, pero empeñado en el equívoco oficio de historiador y filósofo positivista, está esquivando su verdadera vocación: la de literato, ya que es un verdadero poeta, y a la poesía por encima de sus demás inclinaciones debe consagrarse.

La aseveración de Riva Palacio: "Sierra es ante todas cosas un poeta", la recoge al parecer El Diario del Hogar en "Siluetas humorísticas", el 11 de enero de 1882. Unos días después de publicarse la semblanza de Sierra, el autor de la silueta humorística recalca la vocación poética de Sierra.

\section{Justo Sierra}

Es poeta en verdad, y no modesto, está entre los bohemios muy bien quisto, su escuela filosófica es un misto que lo hace aparecer hasta indigesto.

Conoce por el forro hasta el digesto, y la historia escribiera de San Sixto, que en eso de historiar siempre está listo, con una subvención del presupuesto,

14 México cincuenta años de Revolución, México, Fondo de Cultura Económi. ca, 1960 . 
del saber en el campo hace su agosto, que a pesar de su físico robusto su ingenio nunca halló sendero angosto. $Y$ si llega en la vida a ser vetusto, sea un Góngora, un Píndaro o un Ariosto que siempre ha de ser poeta $y \ldots$ esto es

Jusro

Aquella discusión de diciembre de 1881, que dejó maltrecha por un tiempo la amistad Sierra-Riva Palacio, resulta desde luego la motivación poderosa de Los ceros.

La historia y su interpretación, causa directa de ese momentáneo rompimiento, fue una de las preocupaciones tanto de Riva Palacio como de Sierra. Y es en este campo donde a la vuelta de los años, en 1960, los antagonistas Riva Palacio y Sierra se enfrentan nuevamente; ahora, por voluntad de un historiador. Edmundo O'Gorman, con el prestigio de su sabiduría y penetración, en el apartado "Historiografía" analiza la historia dirigida por Riva Palacio, México a través de los siglos, 1884-1889, cuyo segundo tomo escribió, y también la historia de Sierra, México: su evolución social, 1900-1902 y sin menoscabo de uno ni de otro, pues sus tesis, las dos evolucionistas, poco difieren; otorga a Riva Palacio y a Sierra, por igual, el reconocimiento y el mérito de haber cumplido una alta misión: la búsqueda del ser nacional.

A la manera de la semblanza de Justo Sierra, "Cero" se solazó en la pintura de otros personajes connotados de su tiempo. Se detuvo en su físico, imitó su estilo literario, juzgó su obra, ejerció con gracia, con sutil ironía, la crítica literaria, eso sí, sin jamás llegar al escarnio. En sus retratos hay una riqueza de sucesos, noticias, datos, comentarios sobre las corrientes literarias, sobre las filosóficas. También destacan en Los ceros su afanosa indagación por nuestro propio ser, así como la preocupación para señalar algunos de los rasgos peculiares de nuestro carácter, de nuestra expresión literaria; en virtud de todo esto el libro Los ceros, publicado hace cien años, viene a ser una de las obras de esencial valor para conocer y apreciar el panorama cultural de México a fines del siglo xix. 